\title{
Effect of Low Depth Surface Texturing on Friction Reduction in Lubricated Sliding Contact
}

\author{
Haytam Kasem ${ }^{1,2, *}$, Ori Stav ${ }^{1}$, Philipp Grützmacher ${ }^{3}$ (D) and Carsten Gachot ${ }^{4}$ \\ Department of Mechanical Engineering, Technion, Haifa 32000, Israel; oristav@outlook.com \\ Department of Mechanical Engineering, Azrieli College of Engineering, Jerusalem 9103501, Israel \\ 3 Department of Materials Science and Engineering, Functional Materials, Saarland University, \\ Saarbrücken 66123, Germany; philipp.gruetzmacher@uni-saarland.de \\ 4 Institute for Engineering Design and Logistics Engineering E307-3, Vienna University of Technology, \\ Vienna 1060, Austria; carsten.gachot@tuwien.ac.at \\ * Correspondence: mehaytam@technion.ac.il; Tel.: +972-2-659-1829
}

Received: 30 April 2018; Accepted: 11 July 2018; Published: 17 July 2018

\begin{abstract}
Laser surface texturing is an interesting possibility to tailor materials' surfaces and thus to improve the friction and wear properties if proper texture feature sizes are selected. In this research work, stainless steel surfaces were laser textured by two different laser techniques, i.e., the direct laser interference patterning by using a nanosecond pulsed Nd:YAG laser and additionally by an ultrashort pulsed femtosecond Ti:Sa. The as-textured surfaces were then studied regarding their frictional response in a specially designed linear reciprocating test rig under lubricated conditions with a fully formulated 15W40 oil. Results show that dimples with smaller diameter lead to a significant reduction in the coefficient of friction compared to the dimples with a larger diameter and surfaces with a grid-like surface pattern produced by direct laser interference patterning.
\end{abstract}

Keywords: surface texturing; low depth; lubricated sliding contact; friction reduction

\section{Introduction}

Efficient energy is a major and consistently growing concern within all industrial sectors, as well as in the entire society, due to reduced resources and pollution-related issues [1,2]. Nowadays, approximately one-third of the energy resources of the world are consumed just to overcome friction between mechanical components [3].'This is especially the case for Internal Combustion Engines (ICEs), in which friction in the piston-crank mechanism is responsible for $50-70 \%$ of internal mechanical losses [4-6]. Therefore, solutions to reduce friction between mechanical components hold great potential for improving energy efficiency. Tribology plays a key role in optimizing the function of mechanical assemblies by adjusting friction and wear between contacting components undergoing relative motion. Tribological considerations include, but are not limited to, different surface treatments such as plasma [7], coatings [8], chemical modifications [9] and surface texturing [10,11], to name a few. The various applications of surface texturing include introducing of discrete dimples into the manufacturing process to control adhesion [12], adaptation in metal forming processes to control adhesion and diffusion [13,14], optimize friction and wear in mechanical seals [15] and increasing durability [16].

Surface texturing has proven to be an innovative engineering solution that opened the way to enhance the tribological performance of mechanical components [17]. However, the fundamental understanding of how textures function is still lacking despite the recent significant improvements in processing techniques, characterization means, and computational algorithms. This lack of understanding motivated many researchers to investigate the different aspects related to surface 
texturing such as the physical mechanisms involved in reducing friction and wear, the influence of the geometry of texturing and operational parameters.

Many published works in the field aimed at studying the effect of surface texturing on the transitions between the different lubrication regimes. To do so, numerous attempts to record Stribeck-like curves for untextured and textured samples have been reported. Kovalchenko et al. [18] published experimental results showing that using surface texturing strongly accelerates the transition between the boundary and mixed lubrication compared to a reference case. They also showed that the coefficient of friction is significantly reduced under mixed lubrication with textured surfaces. In a similar work, Borghi et al. [19] obtained a friction reduction of $75 \%$ for the laser textured samples. In addition, authors could prove that laser texturing helped to shift the transition from mixed to full film lubrication to lower sliding velocities. Segu et al. [20,21] proposed an innovative approach based on multi-scale textures in an attempt to accelerate transition in the lubrication regimes. Their concept, combining dimples and ellipses, was found to induce faster transitions between lubrication regimes and to reduce the coefficient of friction for conformal conditions as well [20]. Concerning non-conformal conditions, similar effects have been reported for a multiscale texture combining squares and triangles [21].

The effects of surface texturing on hydrodynamic lubrication and bearings have recently been the subject of some interesting review publications [22,23]. Etsion et al. [24] proposed a theoretical model for mechanical seals showing significant enhancement of seal performance when one of the mating seal surfaces contained distributed hemispherical micro-dimples. This work was followed by an experimental model [25] showing that the spherical dimple shape can be further improved and that a certain ratio of dimple depth over dimple diameter can be achieved to maximize the tribological efficiency of laser-textured seal rings tested under oil lubricated contact.

Experimental and theoretical works conducted by Fillon's group [26,27] compared the tribological performances of textured and untextured hydrodynamic thrust bearings under low and high normal loads. The authors could show reductions in friction due to surface texturing up to 30\% under low loads, whereas under high loads, no beneficial effect was found. Some conflicting experimental results were recently reported by Reddyhoff's group [28]. Using a reciprocating test-rig, the authors measured simultaneously friction and film thickness of textured convergent-divergent bearings by means of ultra-thin optical interferometry to measure film thickness. They reported that the surface texture increased friction under full film lubrication conditions, which was attributed to an increase in shear rate.

Extensive works have been done in an attempt to optimize the texturing dimension, shape and aspect ratio in order to improve tribological performances of various mechanical components. A work by Mourier et al. combining experimental and numerical investigations on one individual dimple inside an EHL contact showed that shallow dimples (below $1 \mu \mathrm{m}$ ) led to increased film thickness, while deep dimples caused the film to collapse [29]. The authors pretend that the use of shallow dimples increases the lubricant viscosity, which is fundamental for the generation of thick films in non-conformal contacts. In the same context, other experimental work has shown an increase in film thickness when the width of the dimples is substantially narrower than the contact width [30].

The research group of Galda and Pawlus [31] investigated the influence of spherical and drop-shaped dimples on abrasive wear and seizure resistance. The authors concluded that surface texturing does not always enhance seizure resistance by extension of the oil film lifetime. They tested, in addition, the textures under more severe conditions by adding dust containing $\mathrm{SiO}_{2}$ and $\mathrm{Al}_{2} \mathrm{O}_{3}$ particles to the oil. The results did not show a beneficial effect of the surface texturing in terms of wear resistance. A similar experimental work by Koszelaetal [32] reported that even using textured surfaces, the abrasive particles cause a higher resistance to motion and thus a higher coefficient of friction.

As for using surface texturing in ICEs, a theoretical model of lubrication and friction between laser textured flat modeling piston rings and a cylinder liner has been reported by Etsion's group in 2001 [33]. In this model, the authors showed that the main geometrical parameters of laser texturing 
affecting friction between the piston ring and cylinder liner were the ratio of the dimple depth to the diameter, as well as the area density of the dimples. The model was validated experimentally by the same group [34] using a linear reciprocal test-rig and samples prepared by laser texturing. The laser texturing parameters used in this study were a dimple diameter $100 \mu \mathrm{m}$, a dimple depth of $10 \mu \mathrm{m}$ and an area density of the dimples of $20 \%$. The friction was reduced by $40 \%$ compared to non-textured surfaces. Recently, cross-hatched grooves were introduced on piston liners to prevent seizure under high load high temperature and high-speed conditions $[35,36]$. These cross-hatched grooves provide in-situ localized lubricant reservoirs preventing severe scuffing that could result from lubricant starvation.

In the fabrication process, laser texturing has progressed towards using shorter pulses and nowadays femtosecond lasers are widely used, which have increased flexibility in terms of materials to be processed ranging from metals to ceramics and glasses. One basic limitation of Laser Surface Texturing (LST) is the difficulty to generate complex surface textures including various shapes and sizes. Direct Laser Interference Patterning (DLIP) was developed to address this goal, where multiple laser beam interference is used to create complex surface textures in one single step. On the other hand, many other techniques have been developed and need to be considered when deciding if the use of surface texturing is cost-effective for a certain application. Currently, surface texturing on various forms and shapes is still being extensively investigated for tribological applications by several research groups worldwide. Most of these works are experimental in nature and are based on the idea that enhancing tribological performance of textured surfaces may be attributed to enhanced retention of lubricant in the micro-cavities, which also provide micro-traps to capture wear debris. Theoretical models cite other explanations according to which each micro dimple acts as a micro hydrodynamic bearing to enhance hydrodynamic lubrication [37]. Most of the works published so far concerning ICEs mention an optimum dimple diameter around $100 \mu \mathrm{m}$ and a height of around $10 \mu \mathrm{m}$ (for hydrodynamic conditions). However, smaller sizes of textured surfaces (dimple height and diameter) have not really been studied and are still a matter of some debate.

Therefore, the present study aims at investigating the effect of smaller dimple sizes on the friction of textured surfaces when tested under oil-lubricated conditions. The samples were prepared by Laser Surface Texturing (LST) and tested using a home-made reciprocating test-rig. The results are compared with those obtained for the optimum dimple size presented in Reference [34]. The results show that smaller dimples can be useful to reduce friction. However, regular wear progressively removes the surface textures, leading to a renewed increase of the friction coefficient. This finding suggests a new concept of surface texturing using materials whose wear-rates are very limited, such as ceramics.

\section{Experimental}

\subsection{Samples Description}

In this study, the tested friction pair was composed of a sample made of SAE 1035 steel (hardness $300 \pm 50 \mathrm{HV}$ ) coated with chrome (hardness $1000 \pm 100 \mathrm{HV}$ ) machined into the geometry shown in Figure 1a, and a flat slider made of cast iron used as counter-face of hardness $230 \pm 10 \mathrm{HV}$ (see Figure 1b). The sample has two holes allowing the insertion of thermocouples for the measurement of the temperature variation (see cross-section in Figure 1a). Another hole in the center permits to supply the contact with oil lubricant at a predefined rate (drops per minute). After machining, the surfaces in all samples underwent polishing by lapping to reduce the average roughness to around $R_{\mathrm{a}}=340 \mathrm{~nm}$. The surface roughness is measured by a 3D optical profilometer Wyko NT1100 (Veeco, Tucson, AZ, USA). 

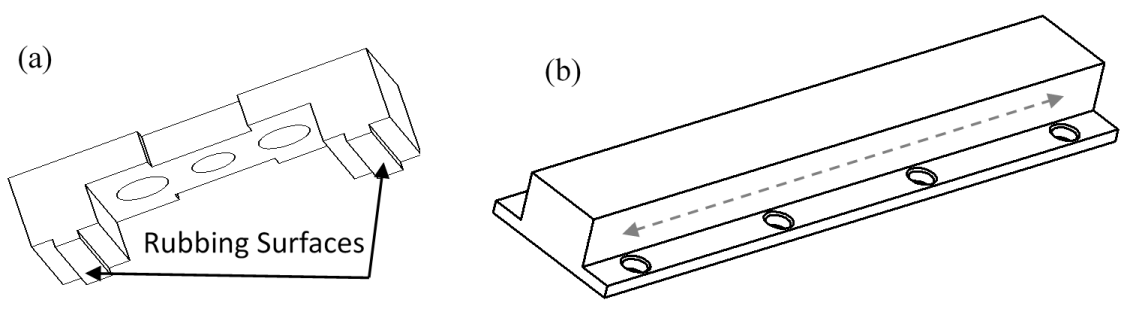

Figure 1. (a) The sample geometry (b) the slider geometry.

\subsection{Laser Texturing}

Four samples with different laser textures were tested in this study. Two samples ( $a$ and $b$ ) with different dimples by an ultrashort-pulsed laser, a grid-like pattern (sample c) by direct laser interference patterning (DLIP) with a nanosecond-pulsed laser, and a reference sample with dimples (sample d) prepared according to the optimized parameters were reported in Reference [34]. Figure 2 presents 3D optical profilometer images and cross-sectional profile plots of the three samples textured $(\mathrm{a}, \mathrm{b}$ and c). All samples were fabricated from the same SAE 1035 steel coated with chrome. For the laser dimples (sample a and b), a linear p-polarized ultrashort-pulsed Ti:Sapphire laser (Spectra-Physics, Spitfire Pro, Darmstadt, Germany) with a pulse duration of $120 \mathrm{fs}$, a repetition rate of $1 \mathrm{kHz}$ and a wavelength of around $800 \mathrm{~nm}$ were used to texture the steel surfaces. For the fabrication of the dimples, three parameters were taken into consideration, (1) the dimple diameter, (2) the dimple depth and (3) the distance between the dimples. The samples were mounted on an $x-y$ motorized table with a micron accuracy. Both dimples were done by irradiating the surfaces with 20 subsequent laser pulses. The number of pulses was set manually. The laser power of the outcoming laser beam was determined by a laser power meter. The laser texturing setup is described in more detail in Reference [38]. The laser fluence for both sample sets was kept constant at around $25 \mathrm{~J} / \mathrm{cm}^{2}$. The distance between the dimples was adjusted to be $200 \mu \mathrm{m}$ and the depth around $4-5 \mu \mathrm{m}$ for both sample textures. Only the dimple diameter varied from $25 \mu \mathrm{m}$ to $30 \mu \mathrm{m}$. This variation was achieved by slightly changing the position of the sample around the focal point of the applied plano-convex lens with a focal length of $74.3 \mathrm{~mm}$.

(a)
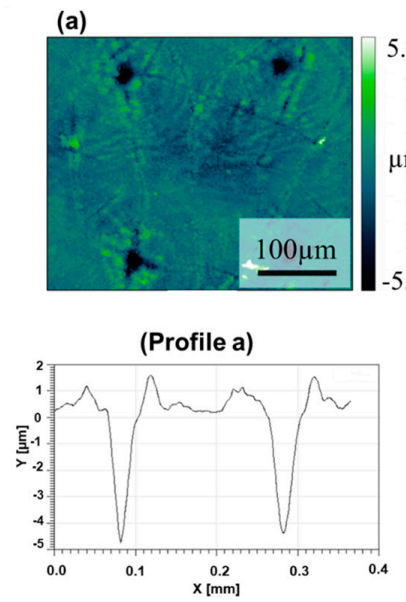

(b)
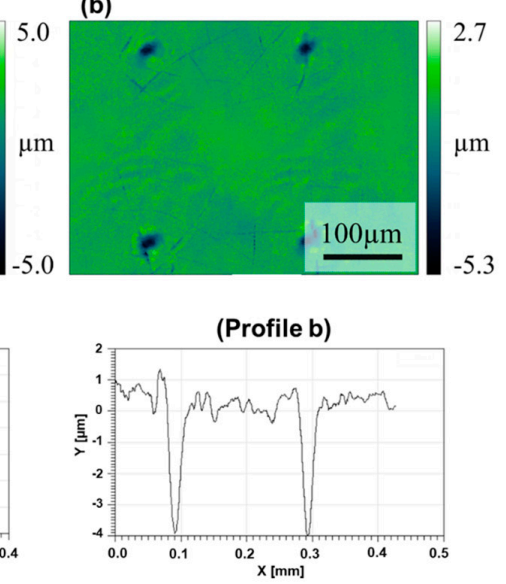

(c)

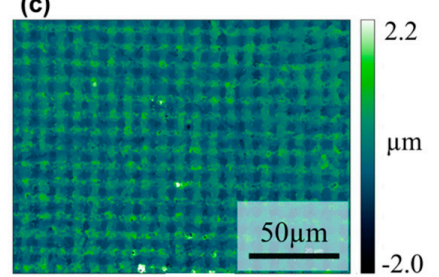

(Profile c)

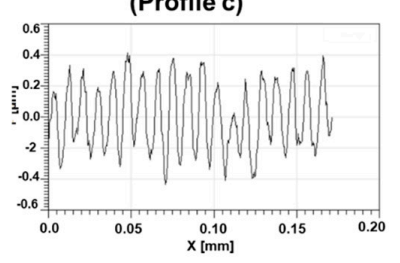

Figure 2. The 3D optical profilometer images and cross-sectional profiles of samples (a) and (b) textured by ultrashort-pulsed laser and sample (c) grid-like pattern by direct laser interference patterning.

The grid-like surface texture (sample c) was produced by a different laser technique, which is called Direct Laser Interference Patterning (DLIP). Here, a nanosecond-pulsed solid state Nd:YAG laser is used with a pulse duration of $10 \mathrm{~ns}$ and repetition rate of $10 \mathrm{~Hz}$. The fundamental wavelength of the system is $1064 \mathrm{~nm}$, which can be varied by a harmonic generator to 512, 355 and $266 \mathrm{~nm}$. For the texturing of the steel samples, a wavelength of $355 \mathrm{~nm}$ was used due to the better laser light absorption. 
The laser energy density (fluence) was set to around $1 \mathrm{~J} / \mathrm{cm}^{2}$. The primary outcoming laser beam was split into two secondary beams by suitable optical beam splitters, which can interfere with each other at the position of the sample surface, thus, leading to a "classical" interference pattern known from fundamental physics with positions of maximum constructive and minimum destructive interference. The resulting topography is a line-like surface texture with a distance between two adjacent maxima or minima positions, which is called periodicity. By turning the sample by a rotation of $90^{\circ}$ and a second texturing step, the overlaying line-like interference patterns equal a grid-like texture geometry. In this case, the periodicity was adjusted to be $9 \mu \mathrm{m}$ with a structural depth of around $1.6 \mu \mathrm{m}$. Previous work in Reference [39] showed for this texture geometry a significantly improved performance under mixed lubrication with PAO 40 oil. For that reason, the same laser texture should be used for the specially designed test rig in order to check the tribological performance in the presence of a fully formulated 15W40 oil. Further details about the DLIP method and the experimental setup can be found in Reference [38].

In addition, as mentioned above, a fourth sample (called in this work Reference) was prepared from the sample steel and textured according to the optimum features parameters as indicated in Reference [34]. According to this reference, the texturing features were found to give the optimum frictional performances (lower friction). Table 1 summarizes the features and sizes of the different samples.

Table 1. The description of feature shape and sizes of the different samples.

\begin{tabular}{ccccc}
\hline Sample & Texture Shape & Dimple Diameter $\mu \mathbf{m}$ & Dimple Depth $\mu \mathrm{m}$ & Distance between Dimples $\mu \mathrm{m}$ \\
\hline $\mathrm{a}$ & Dimples & 25 & $4-5$ & 200 \\
$\mathrm{~b}$ & Dimples & 30 & $4-5$ & 200 \\
$\mathrm{c}$ & Grid-like & - & 1.9 & 9 (periodicity) \\
d-Reference & Dimples & 100 & 10 & 250 \\
\hline
\end{tabular}

\subsection{Test Rig Description}

The frictional performance was assessed using a customized test rig developed at the Technion Tribology Laboratory and extensively described in Reference [34]. The test rig was designed to measure friction force, wear and surface temperature. It allows for the simulation of reciprocating motion of automotive components and is thus suitable for the analysis of the effect of surface texturing on friction and wear under the full and starved lubrication conditions. Figure 3 presents a general view on the assembled test rig. The electric motor $\{1\}$ can be rotated at variable angular velocities, driving the crank mechanism $\{2\}$ that ensures reciprocating motion of the linear stage, which incorporates the slider counter-part $\{3\}$, at speed " $U$ " along the two guides $\{4\}$, fixed on a common bases isolated from the laboratory floor by special elastomer damping pads, which reduce the effect of the test rig vibration on the measured parameters. The normal load is applied by a deadweight $\{5\}$. The friction force is measured by a special device comprising of an elastic beam $\{6\}$ and a proximity probe $\{7\}$. The friction force acting between the rubbing surfaces causes elastic beam deflection, and the proximity probe, which is fixed between the beam and a fixed arm, registers clearance time variations corresponding to friction force variations. The value of the friction force is obtained by timing the output signal of the proximity probe by a calibration factor determined initially by applying accurate weights. The average friction is obtained by online integration of the absolute value of the time-dependent friction force over one cycle lope. The friction force resolution was estimated to be around $0.1 \mathrm{~N}$, with an accuracy of $5 \%$. Reciprocating speed measurements, including average speed and crankshaft rotation frequency, are registered with an optical gauge. In order to guarantee suitable contact conformity between the samples, a holder mechanism was specially designed to ensure self-alignment of the sample with respect to the counterpart plane slider. It also allows for the application of a normal load (NL) on the holder, as well as lubricant feeding to the contact zone via the oil conduit at its center, and leading out through the wires of thermocouples embedded in the holder. 


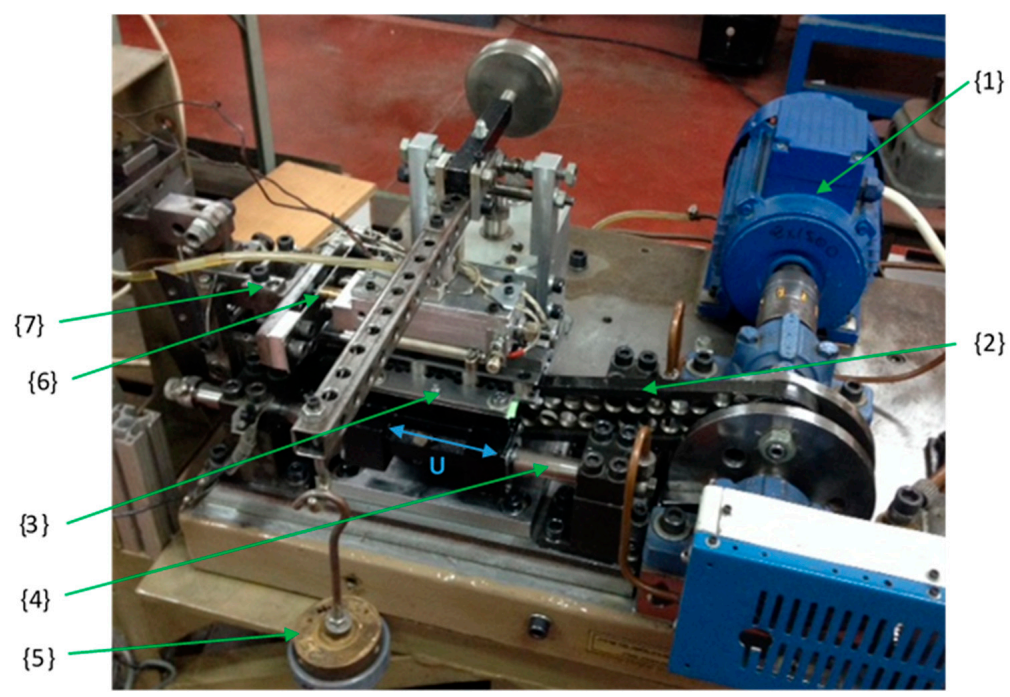

Figure 3. The general overview on the assembled test rig.

The measurements are sampled with a multifunctional data acquisition board Lab-PC-1200 (National Instruments Co., Austin, TX, USA) and processed using a LabVIEW software package (National Instruments Co.). Finally, a special lubrication and cooling system, designed to circulate oil through the hollow guides, reduces friction in the guides' linear bearings and removes heat from the guides' friction surfaces, ultimately maintaining stability, longevity, and accuracy of the reciprocating motion. The test rig has been recently slightly modified to improve its performance and accuracy by reducing the mass of moving parts, particularly of the crank mechanism.

\subsection{Test Procedure}

The friction test begins by putting the sample in contact with the slider under a predefined contact pressure applied by the deadweight. Then, the electric motor drives the slider into a reciprocating motion at a velocity " $U$ ". During friction tests, the electrical heaters are used to heat up the sample to a temperature ranging between 60 and $70{ }^{\circ} \mathrm{C}$ (the temperature is measured thanks to thermocouples located at $4 \mathrm{~mm}$ below the friction surface). The contact is lubricated by a fully formulated $15 \mathrm{~W} 40$ mineral oil (density at $80{ }^{\circ} \mathrm{C} 0.8414 \mathrm{~g} / \mathrm{cm}^{3}$; kinematic viscosity at $80{ }^{\circ} \mathrm{C} 23 \mathrm{~mm} / \mathrm{s}$; zinc mass $0.126 \%$; phosphorus mass $0.155 \%$ and sulphated ash mass $0.99 \%$ ) dropping out via a nozzle at a constant rate of three drops per minute.

Table 2 summarizes the operation conditions for the friction tests. Each test has been repeated three times to make sure that it has a good repeatability (for reliability and validation). The contact pressure of $0.15 \mathrm{MPa}$ corresponds to the low working pressures between the piston-ring and cylinder liner obtained by the elasticity of the piston ring [40]. The rotational speed of the motor was adjusted to $500 \mathrm{rpm}$ (highest possible speed of the experimental test-rig while avoiding dynamic disturbing), corresponding to the average sliding speed, between the slider and the specimen, of $1.75 \mathrm{~m} / \mathrm{s}$. Calculations are based on the stroke length of $0.1 \mathrm{~m}$. It should be noticed here that the surface topography has been measured after the friction test for the different specimens, as well.

Table 2. The summary of experimental conditions.

\begin{tabular}{cc}
\hline Operation Parameters & Range \\
\hline Motor Rotation Speed $[\mathrm{RPM}]$ & 500 \\
Contact Pressure $[\mathrm{MPa}]$ & 0.15 \\
Oil Rate [Drops $/$ Minute] & 3 \\
Near Surface Temperature $\left[{ }^{\circ} \mathrm{C}\right]$ & $60-70$ \\
\hline
\end{tabular}


Table 2. Cont

\begin{tabular}{cc}
\hline Operation Parameters & Range \\
\hline Ambient Temperature $\left[{ }^{\circ} \mathrm{C}\right]$ & $24-25$ \\
Relative humidity [\%] & $45-55$ \\
Oil Type & $15 \mathrm{~W} 40$ \\
Test duration [s] & 600 \\
\hline
\end{tabular}

\section{Results and Discussion}

As mentioned above, four samples described in Section 2.3 above have been tested on the reciprocating test-rig under the operational conditions mentioned in Table 2 . The typical variation of the friction force versus time over several successive crank revolutions for sample (a) is presented in Figure 4 . The alternation of negative and positive values is related to the reciprocating motion of the slider causing the positive and negative deflections of the elastic beam. The resolution of the measured values presented in Figure 4 is around $0.06 \mathrm{~N}$ and the accuracy is $3 \%$.

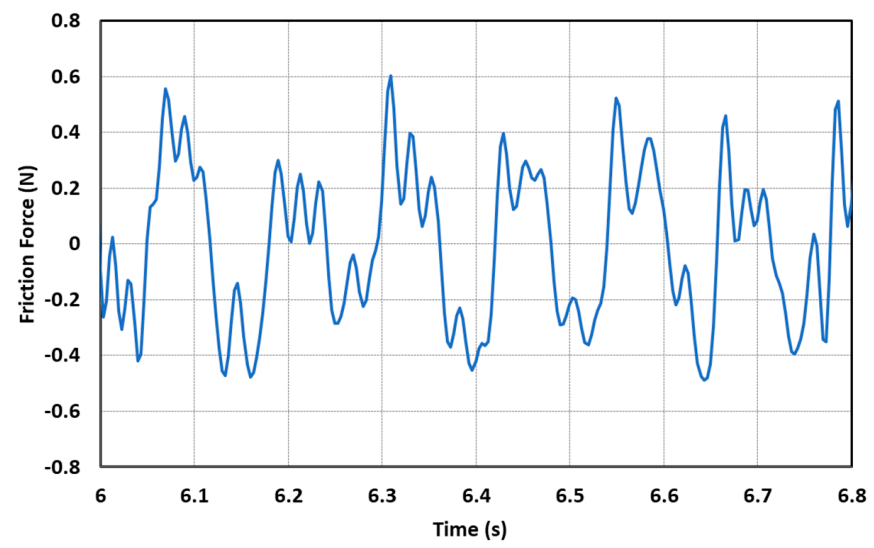

Figure 4. The typical variation of the friction force as a function of time during successive revolutions obtained under a normal load corresponding to $0.5 \mathrm{MPa}$ and a rotational speed of 500 RPM (Sample a).

The average friction coefficient is obtained by dividing the measured friction force by the applied normal load then integrating the absolute value of the time-dependent friction coefficient online over one cycle. The variation of the average absolute value of the friction coefficient over the test time progress is calculated and displayed in Figure 5.

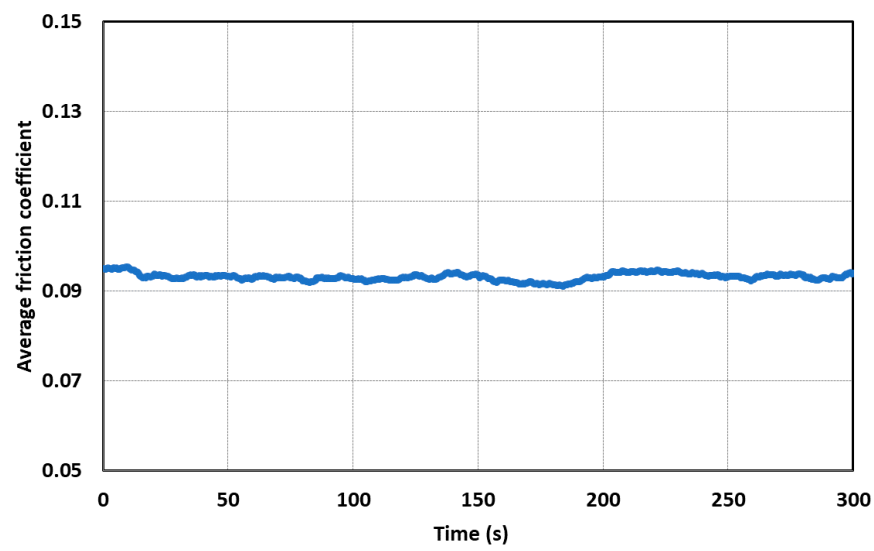

Figure 5. The variation of the average absolute value of friction coefficient over the test time progress obtained under a normal load corresponding to $0.5 \mathrm{MPa}$ and a rotational speed of $500 \mathrm{RPM}$ (Sample a). 
As can be seen in Figure 5, the average friction coefficient stabilizes and remains almost constant over the test progress. To better estimate the average effect of the different surface textures on the friction performances during reciprocating motion, the absolute values of friction coefficient were averaged for the different samples and error bars were computed and displayed in Figure 6. As can be seen, samples a and b present a lower friction coefficient compared to the d-reference sample. In contrast, sample c (grid-like surface texture) presents a higher friction coefficient. These results indicate clearly that smaller dimples in surface texturing can be useful to achieve a lower friction. The results by Greiner and Braun et al. under mixed lubrication conditions also showed that a smaller dimple diameter resulted in lower friction [41,42]. The amount of friction reduction highly depends on the number of dimple edges being introduced and the possibility to set up a certain lubricant flow in the dimples. As far as boundary lubrication is concerned, there is a strong dependency on the number of dimples and the connected roughness and edge stresses. Because of that, it is a balance between dimple density, size, and shape. Smaller dimples with a typical area density between 5-8\% seem to be beneficial because the ability to retain lubricant in the pockets is higher and so friction is lower [10]. Though giving a lower friction coefficient compared to the optimum texturing features in Reference [34], however, due to the shallow depth of the dimples in samples a and b, the progressive wear of the used materials in this study (steel SAE 1035) might eliminate the surface texturing and thus re-increase friction. It is legitimate to suppose that these shallow textures can be adapted for harder materials, in which wear is limited to reduce friction under lubricated contact conditions.

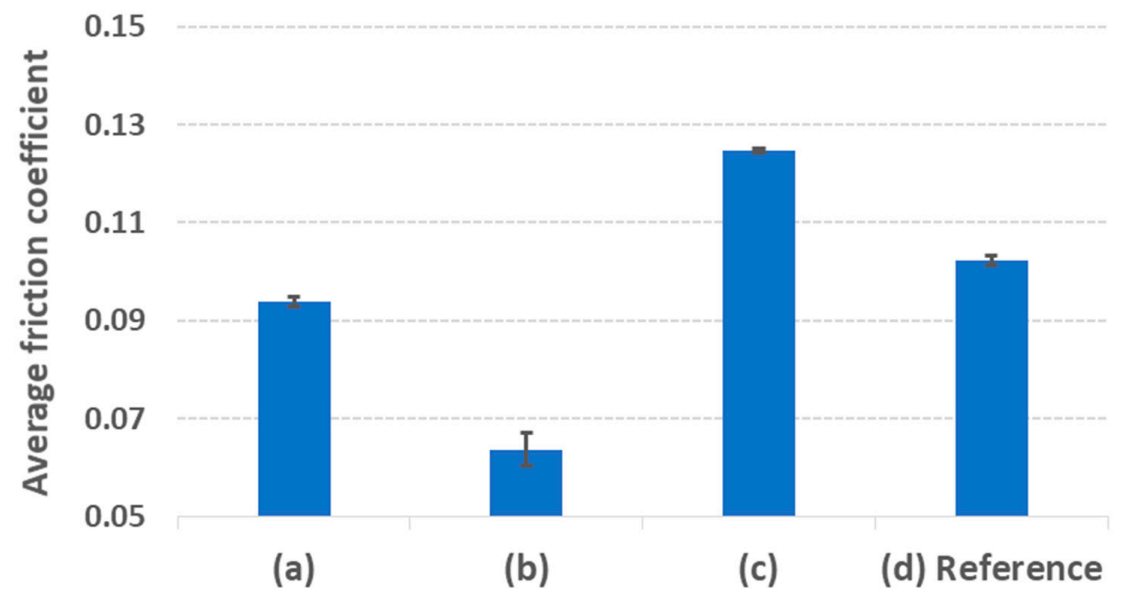

Figure 6. The average friction coefficient for the different tested samples.

\section{Conclusions}

The effect of small and shallow dimples size on the friction performance of textured surfaces under reciprocal lubricated contact condition was studied experimentally. Four samples made of steel and coated with chrome were textured with different small shapes of dimples (by using an ultrashort pulsed laser) and grid-like surface texture (applying direct laser interference patterning). The friction tests were conducted on a home-made reciprocal test-rig under a contact pressure of $0.15 \mathrm{MPa}$, a motor rotation speed of 500 RPM, a contact temperature ranging between $60-70{ }^{\circ} \mathrm{C}$ and a fully formulated oil (15W40) feeding rate of 3 drops per minute. The absolute average friction coefficient was computed for each cycle (loop). The results are compared with those obtained for a fourth sample made of the same material but different textured according to the optimal dimples size (diameter $100 \mu \mathrm{m}$ and depth $10 \mu \mathrm{m}$ ) proposed by Ryk et al. in Reference [34]. The following observations were made:

- Under the considered experimental conditions, small dimples seem to be useful to achieve lower friction compared to the optimum size presented in Reference [34]. 
- The grid-like surface texture is found to cause high friction, even higher than the optimum texturing size in Reference [34] when tested under the same conditions.

- While small dimple sizes present the lower friction coefficient, however, due to wear, the surface textures are progressively removed, which might re-increase the friction.

- Based on the finding of this work, surface textured with small and shallow dimples size could be used to reduce friction in lubricated contact with first body materials having high wear resistance such as ceramics.

Author Contributions: H.K. and C.G. are the PIs of this project, they participated in the Conceptualization and Administration of the project. Writing-Original Draft Preparation was done by H.K. and Writing-Review \& Editing was done by C.G. O.S. and P.G. participated in the Investigation, Data Curation and Formal Analysis.

Funding: This research received no external funding.

Conflicts of Interest: The authors declare no conflict of interest.

\section{References}

1. Holmberg, K.; Siilasto, R.; Laitinen, T.; Andersson, P.; Jäsberg, A. Global energy consumption due to friction in paper T. machines. Tribol. Int. 2013, 62, 58-77. [CrossRef]

2. Khebda, M.; Chichinadze, A.V. Handbook of Tribotechnology; Mashinostroenie: Moscow, Russia, 1989.

3. Holmberg, K.; Erdemir, A. Influence of tribology on global energy consumption, costs and emissions. Friction 2017, 5, 263-284. [CrossRef]

4. Dowson, D. History of Tribology; Longman Group Limited: Harlow, UK, 1979.

5. Pinkus, O.D.F.; Wilcock, D.F. The role of tribology in energy conservation. Lubr. Eng. 1978, 34, 599-610.

6. Heywood, J.B. Internal Combustion Engine Fundamentals; Mcgraw-Hill: New York, NY, USA, 1988.

7. Hegemann, D.; Brunner, H.; Oehr, C. Plasma treatment of polymers for surface and adhesion improvement. Nucl. Instrum. Methods Phys. Res. Sect. B 2003, 208, 281-286. [CrossRef]

8. Holmberg, K.; Mathews, A. Coatings tribology: A concept, critical aspects and future directions. Thin Solid Films. 1994, 253, 173-178. [CrossRef]

9. Varenberg, M.; Ryk, G.; Yakhnis, A.; Kligerman, Y.; Kondekar, N.; McDowell, M.T. Mechano-Chemical Surface Modification with $\mathrm{Cu}_{2} \mathrm{~S}$ : Inducing Superior Lubricity. Tribol. Lett. 2016, 64, 28. [CrossRef]

10. Gachot, C.; Rosenkranz, A.; Hsu, S.M.; Costa, H.L. A critical assessment of surface texturing for friction and wear improvement. Wear 2017, 372, 21-41. [CrossRef]

11. Etsion, I. State of the Art in Laser Surface Texturing. J. Tribol. 2005, 127, 248-253. [CrossRef]

12. Baumgart, P.; Krajnovich, D.J.; Nguyen, T.A.; Tam, A.C. A new laser texturing Technique for high performance magnetic disk drives. IEEE Trans. Magn. 1995, 31, 2946-2951. [CrossRef]

13. Ike, H. Nanosomic surface texture formed by indentation and sliding of a smooth wedge tool. Wear 2005, 258, 1404-1410. [CrossRef]

14. Costa, H.L;; Hutchings, I.M. Effects of die surface patterning on lubrication in strip drawing. J. Mater. Process. Technol. 2009, 209, 1175-1180. [CrossRef]

15. Ling, W. Use of structured surfaces for friction and wear control on bearing surfaces. Surf. Topogr. Metrol. Prop. 2014, 2, 043001. [CrossRef]

16. Yu, H.; Wang, X.; Zhou, F. Geometric shape effects of surface texture on the generation of hydrodynamic pressure between conformal contacting surfaces. Tribol. Lett. 2010, 37, 123-130. [CrossRef]

17. Etsion, I. Improving tribological performance of mechanical components by laser surface texturing. Tribol. Lett. 2004, 17, 733-737. [CrossRef]

18. Kovalchenko, A.; Ajayi, O.; Erdemir, A.; Fenske, G. Friction and wear behavior of laser textured surface under lubricated initial point contact. Wear 2011, 271, 1719-1725. [CrossRef]

19. Borghi, A.; Gualtieri, E.; Marchetto, D.; Moretti, L.; Valeri, S. Tribological effects of surface texturing on nitriding steel for high-performance engine applications. Wear 2008, 265, 1046-1051. [CrossRef]

20. Segu, D.Z.; Choi, S.G.; Choi, J.H.; Kim, S.S. The effect of multi-scale laser textured surface on lubrication regime. Appl. Surf. Sci. 2013, 270, 58-63. [CrossRef]

21. Segu, D.Z.; Kim, S.S. Influence on friction behavior of micro-texturing under lubricated non-conformal contact. Meccanica 2014, 49, 483-492. [CrossRef] 
22. Gropper, D.; Wang, L.; Harvey, T.J. Hydrodynamic lubrication of textured surfaces: A review of modeling techniques and key findings. Tribol. Int. 2016, 94, 509-529. [CrossRef]

23. Etsion, I. Modeling of surface texturing in hydrodynamic lubrication. Friction 2013, 1, 195-209. [CrossRef]

24. Etsion, I.; Halperin, G.; Greenberg, Y. Increasing Mechanical Seal Life with Laser-Textured Seal Faces. In Proceedings of the 15th International Conference on Fluid Sealing BHR Group, Maastricht, The Netherlands, 16-18 September 1997; pp. 3-11.

25. Etsion, I.; Halperin, G.; Brizmer, V.; Kligerman, Y. Experimental investigation of laser surface textured parallel thrust bearings. Tribol. Lett. 2004, 17, 295-300. [CrossRef]

26. Dobrica, M.B.; Fillon, M.; Pascovici, M.D.; Cicone, T. Optimizing surface texture for hydrodynamic lubricated contacts using a mass-conserving numerical approach. Proc. Inst. Mech. Eng. J 2010, 22, 737-750. [CrossRef]

27. Henry, Y.; Bouyer, J.; Fillon, M. An experimental analysis of the hydrodynamic contribution of textured thrust bearings during steady-state operation: A comparison with the untextured parallel surface configuration. Proc. Inst. Mech. Eng. J 2014, 229, 362-375. [CrossRef]

28. Vladescu, S.C.; Olver, A.V.; Pegg, I.G.; Reddyhoff, T. The effects of surface texture inreciprocating contacts-An experimental study. Tribol. Int. 2015, 82, 28-42. [CrossRef]

29. Mourier, L.; Mazuyer, D.; Ninove, F.P.; Lubrecht, A.A. Lubrication mechanisms with laser-surface-textured surfaces in elastohydrodynamic regime. Proc. Inst. Mech. Eng. J. 2010, 224, 697-711. [CrossRef]

30. Krupka, I.; Hartl, M.; Zimmerman, M.; Houska, P.; Jang, S. Effect of surface Texturing on elastohydrodynamically lubricated contact under transient speed conditions. Tribol. Int. 2011, 44, 1144-1150. [CrossRef]

31. Galda, L.; Dzierwa, A.; Sep, J.; Pawlus, P. The effect of oil pockets shape and distribution on seizure resistance in lubricated sliding. Tribol. Lett. 2010, 37, 301-311. [CrossRef]

32. Koszela, W.; Dzierwa, A.; Galda, L.; Pawlus, P. Experimental investigation of oil pockets effect on abrasive wear resistance. Tribol. Int. 2012, 46, 145-153. [CrossRef]

33. Ronen, A.; Etsion, I.; Kligennan, Y. Friction-Reducing Surface-Texturing in Reciprocating Automotive Components. Tribl. Trans. 2001, 44, 359-366. [CrossRef]

34. Ryk, G.; Kligerman, Y.; Etsion, I. Experimental Investigation of Laser Surface Texturing for Reciprocating Automotive Components. Tribol. Trans. 2002, 45, 444-449. [CrossRef]

35. Spencer, A. Optimizing Surface Texture for Combustion Engine Cylinder Liners. Ph.D. Thesis, Luleå Technical University, Luleå, Sweden, 2010.

36. Schmid, D.M.J. Large engine cylinder honing as a contribution to emissions reduction. MTZ Ind. 2013, 3, 48-53. [CrossRef]

37. Kligerman, Y.; Etsion, I. Analysis of the Hydrodynamic Effects in a Surface Textured Circumferential Gas Seals. Tribol. Trans. 2001, 44, 472-478. [CrossRef]

38. Lasagni, A.F.; Gachot, C.; Trinh, K.E.; Hans, M.; Rosenkranz, A.; Roch, T.; Lang, V. Direct laser interference patterning, 20 years of development: From the basics to industrial applications. In Laser-Based Micro-and Nanoprocessing XI; International Society for Optics and Photonics: Bellingham, WA, USA, 2017; Volume 10092, p. 1009211.

39. Rosenkranz, A.; Heib, T.; Gachot, C.; Mücklich, F. Oil film lifetime and wear particle analysis of laser-patterned stainless steel surfaces. Wear 2015, 334, 1-12. [CrossRef]

40. Dowson, D. Piston Assemblies; Background and lubrication analysis. Elsevier 1993, 26, 213-240. [CrossRef]

41. Braun, D.; Greiner, C.; Schneider, J.; Gumbsch, P. Efficiency of laser surface texturing in the reduction of friction under mixed lubrication. Tribol. Int. 2014, 77, 142-147. [CrossRef]

42. Greiner, C.; Merz, T.; Braun, D.; Codrignani, A.; Magagnato, F. Optimum dimple diameter for friction reduction with laser surface texturing: The effect of velocity gradient. Surf. Topogr. Metrol. Prop. 2015, 3, 044001. [CrossRef]

(C) 2018 by the authors. Licensee MDPI, Basel, Switzerland. This article is an open access article distributed under the terms and conditions of the Creative Commons Attribution (CC BY) license (http:/ / creativecommons.org/licenses/by/4.0/). 